\title{
One-Step Synthesis of High-Quality Water-Soluble CdSe Quantum Dots Capped by $N$-Acetyl-L-cysteine via Hydrothermal Method and Their Characterization
}

\author{
Chunjin Wei, Jinyu Li, Fang Gao, Shuxia Guo, Yongcui Zhou, and Dan Zhao \\ College of Pharmacy, South-Central University for Nationalities, Hubei, Wuhan 430074, China \\ Correspondence should be addressed to Dan Zhao; wqzhdpai@163.com
}

Received 11 August 2014; Revised 24 October 2014; Accepted 27 October 2014

Academic Editor: Qingrui Zhang

Copyright (C) 2015 Chunjin Wei et al. This is an open access article distributed under the Creative Commons Attribution License, which permits unrestricted use, distribution, and reproduction in any medium, provided the original work is properly cited.

\begin{abstract}
Novel water-soluble CdSe quantum dots (QDs) have been prepared with $N$-acetyl-L-cysteine as new stabilizer through a one-step hydrothermal route. The influence of experimental conditions, including reaction time, molar ratio of reactants, and $\mathrm{pH}$ value, on the luminescent properties of the obtained CdSe QDs has been systematically investigated. The characterization of as-prepared QDs was carried out through different methods. In particular, we realized qualitative and semiquantitative studies on CdSe QDs through X-ray photoelectron spectroscopy and electron diffraction spectroscopy. The results show that the as-prepared CdSe QDs exhibit a high quantum yield (up to $26.7 \%$ ), high stability, and monodispersity and might be widely used in biochemical detection and biochemical research.
\end{abstract}

\section{Introduction}

Quantum dots (QDs) are nanomaterials usually composed of II-VI or III-V elements [1]. The unique optical properties caused by their small diameters $(1-10 \mathrm{~nm})$ lead to their promising applications in biochemistry detections [2], biological labeling [3], cell imaging in vivo [4], solar battery [5], and electronic equipment [6].

Among QDs made up of II-VI group elements, CdSe QDs have attracted broad interests due to their fluorescence emission in visible light range [7]. Though selenium and telluride are both VI group elements, the spectra properties of the prepared CdSe QDs are much worse than those of CdTe QDs, because those CdSe QDs with sulphydryl compounds (such as thioglycolate and cysteine) as stabilizers possess low quantum yields (QYs) and wide emission full width at half maximum (FWHM) $(>100 \mathrm{~nm})$ [8]. Since synthesis method and the used stabilizer would greatly affect the optical properties of prepared QDs, the studies on the choice of stabilizer during the synthesis process of water-soluble QDs have been widely reported [8], including thiomalic acid, thioglycolate, $\mathrm{N}$-(2-mercaptopropionyl)glycine, glutathione, and L-cysteine. The reports on $\mathrm{N}$-acetyl-L-cysteine (NAC) as the stabilizer during the synthesis, however, have not been seen in literature. NAC is known as an antioxidant and impurity removal reagent and can be used to protect cells from oxidation and QDs induced cytotoxicity $[9,10]$. Additionally, it possesses good water-solubility, is nonvolatile and inodorous, have excellent biocompatibility, and is friendly to the environment and its users. The commonly employed methods for direct synthesis of QDs in aqueous solution are reflux method [11-13] and microwave radiation method [14-16]. These methods, however, have obvious weaknesses: the reflux method requires long reaction time and the prepared QDs have low QYs and wide FWHM, while the microwave radiation method requires complex synthesis equipment, which greatly limits their practical applications. The hydrothermal route [17] is a newly developed hydrothermal route for direct synthesis of water-soluble QDs in an airtight reaction vessel (autoclave) under high pressure and temperature. The high temperature (usually supercritical temperature or close to critical temperature) speeds up the growth of QDs, decreases the surface defects, and thus reduces the probability of fluorescence quenching induced by irradiative decay and improves the fluorescence efficiency of prepared QDs [9]. Compared with core/shell CdSe/CdS QDs 
prepared by two-step method, the hydrothermal method allows rapid synthesis of QDs through one-step process with stabilizer simultaneously as the sulfur source. The simple synthesis process is thus an ideal method to improve the optical property of prepared QDs.

In this paper, we report the synthesis of high-quality water-soluble CdSe QDs through one-step hydrothermal method and discuss the impacts of important experiment parameters (reaction time, $\mathrm{pH}$, feed ratio, etc.) on the optical properties of prepared QDs. The synthesized CdSe QDs have been characterized through fluorescence spectroscopy, UV absorption spectroscopy, high resolution transmission electron microscopy (HRTEM), X-ray powder diffraction (XRD), X-ray photoelectron spectroscopy (XPS), and electron diffraction spectroscopy (EDS), and their morphology, crystal structure, optical properties, and element composition have been studied with these means. The prepared CdSe QDs meet the requirements for the fluorescence materials in biological labeling and will surely have promising applications in biochemical detection and biomedical researches.

\section{Experimental Procedures}

2.1. Chemicals. Selenium (reagent powder) was purchased from Shanghai Mei Xing Chemical Co., Ltd. $\mathrm{CdCl}_{2}$, rhodamine $6 \mathrm{G}$, and sodium borohydride $\left(\mathrm{NaBH}_{4}\right)$ were obtained from Sinopharm Chemical Reagent. NAC was purchased from Sigma. All chemicals used were of analytical grade or of the highest purity available. All solutions were prepared using Milli-Q water (Millipore) as the solvent.

2.2. Preparation of CdSe QDs. Sodium borohydride $(0.0250 \mathrm{~g})$ and selenium powder $(0.0100 \mathrm{~g})$ were dissolved in $3 \mathrm{~mL}$ ultrapure water in a $5 \mathrm{~mL}$ one-necked flask to produce sodium hydroselenide (NaHSe, $0.0422 \mathrm{~mol} / \mathrm{L}$ ). A small outlet connected to the flask was kept open to discharge the pressure from the resulting hydrogen. After approximately $30 \mathrm{~min}$, the black selenium powder disappeared, and the small outlet was then completely shut. Fresh NaHSe solution was then kept in freezer for further use.

$\mathrm{CdCl}_{2}(6.4 \mathrm{mmol} / \mathrm{L})$ and a certain amount of NAC were dissolved in $50 \mathrm{~mL}$ of deionized water and stirred vigorously for 20 minutes. The precursor solution was adjusted to desired value ( 8.5 to 11 ) by stepwise addition of $1.0 \mathrm{~mol} / \mathrm{L}$ of $\mathrm{NaOH}$. Subsequently, the fresh NaHSe solution $(0.0422 \mathrm{~mol} / \mathrm{L})$ was added to a $\mathrm{N}_{2}$-saturated mixture of $\mathrm{CdCl}_{2}$ and NAC with a certain percentage and stirred vigorously for 5 minutes. The $\mathrm{Cd}^{2+}$ concentration was $6.4 \mathrm{mmol} / \mathrm{L}$ in a total volume of $50 \mathrm{~mL}$. The molar ratios of $\mathrm{NAC} / \mathrm{Cd}^{2+}$ used in our experiment are $1.2: 1,2.0: 1,2.4: 1,3.0: 1$, and $3.6: 1$, in sequence. The molar ratios of $\mathrm{Se}^{2+} / \mathrm{Cd}^{2+}$ used in our experiment are $0.025: 1,0.05: 1,0.10: 1,0.15: 1$, and $0.20: 1$, in sequence. Finally, the resulting mixture was put into a $50 \mathrm{~mL}$ Teflon-lined stainless steel autoclave. It was loaded in an oven at $200^{\circ} \mathrm{C}$ for a specified time (50 to $70 \mathrm{~min}$ ) and then cooled to the room temperature by a hydrocooling process.

To remove NAC-Cd complexes at the end of the synthesis, cold 2-propanol was added to the reaction mixture to precipitate NAC-capped CdSe QDs. The as-prepared products were dried overnight under vacuum at $40^{\circ} \mathrm{C}$ for further experiments.

2.3. Characterization. UV-visible absorption spectra were acquired with a Lambda-35 UV/visible spectrophotometer (PerkinElmer Company) to determine the absorption of QDs. Fluorescence spectra were recorded on a LS55 spectrofluorometer (PerkinElmer Company). All optical measurements were performed at room temperature under ambient conditions. The HRTEM sample was prepared by dropping an aqueous CdSe QDs solution onto an Agar carbon-coated copper grid (400 meshes) with the excess solvent evaporated. The HRTEM image was obtained via JEM-2100 (HR) transmission electron microscope (Japan Electron Optics Laboratory CO., Ltd.). XRD spectrum was recorded on a Shimadzu XRD-2000 X-ray diffractometer. EDS spectrum was captured with an FEI Quanta 200 scanning electron microscope equipped with an energy dispersive $\mathrm{X}$-ray spectrometer. XPS measurements were acquired with a Leybold Heraeus SKL 12 X-ray photoelectron spectrometer. The QY of CdSe QDs was measured according to the literature [18]. Rhodamine 6G in ethanol was chosen as the reference standard $(\mathrm{QY}=95 \%)$.

\section{Results and Discussion}

3.1. Influence of Reaction Time. Since the optical properties of the prepared CdSe QDs are greatly influenced by a series of experimental parameters, such as reaction time, feeding ratio of the reaction reagents, and the $\mathrm{pH}$ value, the optimizing experiments were carried out in order to acquire the highquality QDs.

The reaction temperature is a very important factor that influences optical properties of the prepared QDs. The low temperature $\left(<170^{\circ} \mathrm{C}\right)$ would decrease the reaction rate, prolong the reaction time, and consequently lead to the low QYs of the prepared QDs. The high reaction temperature, on the other hand, will produce white precipitates in the autoclave together with pungent odor, which may be the result of the decomposition of NAC under such high temperature, losing its ability as stabilizer. Therefore, the optimum reaction time is in the range of 170 to $210^{\circ} \mathrm{C}$.

With other reaction parameters fixed $([\mathrm{Cd}]=$ $6.4 \mathrm{mmol} / \mathrm{L}, n(\mathrm{Cd}): n(\mathrm{Se}): n(\mathrm{NAC})=1.0: 0.05: 3.0, \mathrm{pH}=$ 9 , and reaction temperature at $200^{\circ} \mathrm{C}$ ), experiments were carried out to examine the impact of reaction time (50$70 \mathrm{~min}$ ) upon the quality of prepared CdSe QDs. As shown in Figure 1, different from the obvious redshifts of the emission peak of NAC-capped CdTe QDs with the prolonged reaction time [17], the emission peaks of CdSe QDs show no obvious shift $(540-555 \mathrm{~nm})$ with the increase of reaction time, and their FWHM of fluorescence spectra $(26-31 \mathrm{~nm})$ as well as absorption peaks of UV spectra (516-532 nm) also generally stay stable. The QYs of the prepared QDs, however, are greatly influenced by the reaction time. The CdSe QDs prepared at $65 \mathrm{~min}$ possess the highest QY. The mechanism of this phenomenon is that at the initial stage of the reaction, NAC 


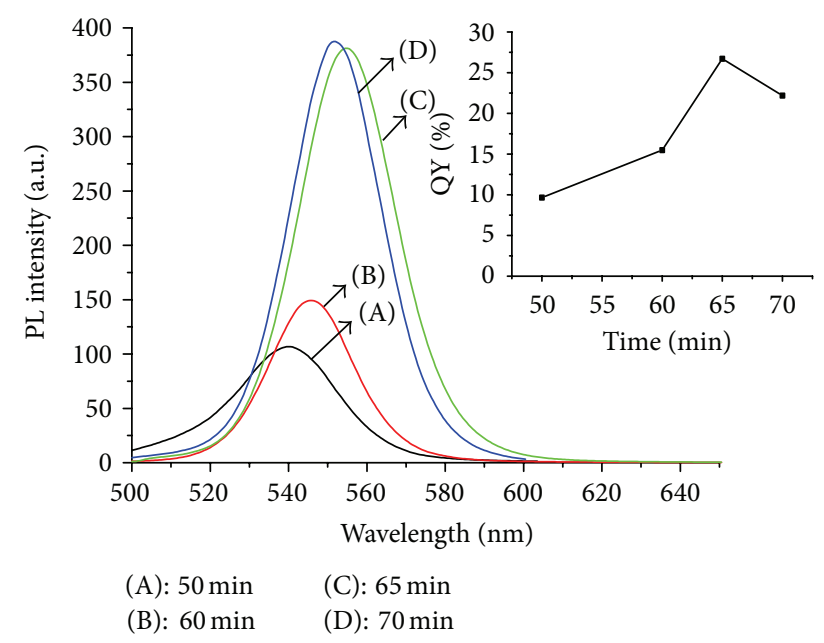

FIGURE 1: Corrected PL spectra of NAC-capped CdSe QDs prepared at various reaction times; the inset shows the QYs of these prepared QDs.

combines with the surface of CdSe QDs as the ligand, while with the reaction continuing, NAC decomposes under high temperature, releases $\mathrm{S}^{2-}$ into the solution, and forms CdS with the Cd ions on the surface of CdSe QDs. The formed CdS through alloying reaction can decrease the surface defects of the QDs and thus improves their QYs. When the reaction time is over $65 \mathrm{~min}$, the overdecomposition of NAC would deprive its ability as stabilizer and thus fails to synthesize water-soluble QDs [9].

3.2. Influence of Molar Ratio of Se to $\mathrm{Cd}$. The molar ratio of Se to Cd during the synthesis would greatly influence the element composition of the prepared QDs and thus impact the QYs of the prepared CdSe QDs. With other experiment parameters fixed $([\mathrm{Cd}]=6.4 \mathrm{mmol} / \mathrm{L}, n(\mathrm{Cd}): n(\mathrm{NAC})=$ $1.0: 3.0, \mathrm{pH}=9$, reaction temperature at $200^{\circ} \mathrm{C}$, and reaction time at $65 \mathrm{~min}$ ), the molar ratios of Se to $\mathrm{Cd}$ were gradually increased from 0.025 to 0.20 . As shown in Figure 2, the change of molar ratio of Se to Cd does not produce obvious influence upon the emission peak of prepared CdSe QDs, with their emission peak mainly at approximately $554 \mathrm{~nm}$, but it shows great impact on the QYs of prepared QDs. The QYs of QDs reach the maximum when $n(\mathrm{Se}) / n(\mathrm{Cd})$ is at 0.05 . The high molar ratio of Se to Cd would increase Se content in the prepared CdSe QDs, and the easy oxidation of Se on the surface of QDs would produce many nonradioactive combination sites, leading to the degradation of QY.

3.3. Influence of $p H$ of Precursor Solution. Since QDs are prone to aggregate under acid environment, the impacts of alkaline condition ( $\mathrm{pH}=8.5-11)$ of the precursor solution on the prepared CdSe QDs were the focus of our research. As shown in Figure 3, with other synthesis parameters fixed $([\mathrm{Cd}]=6.4 \mathrm{mmol} / \mathrm{L}, n(\mathrm{Cd}): n(\mathrm{Se}): n(\mathrm{NAC})=1.0: 0.05: 3.0$, reaction time at $65 \mathrm{~min}$, and reaction temperature at $200^{\circ} \mathrm{C}$ ), the result shows that the $\mathrm{pH}$ also sets no obvious impact

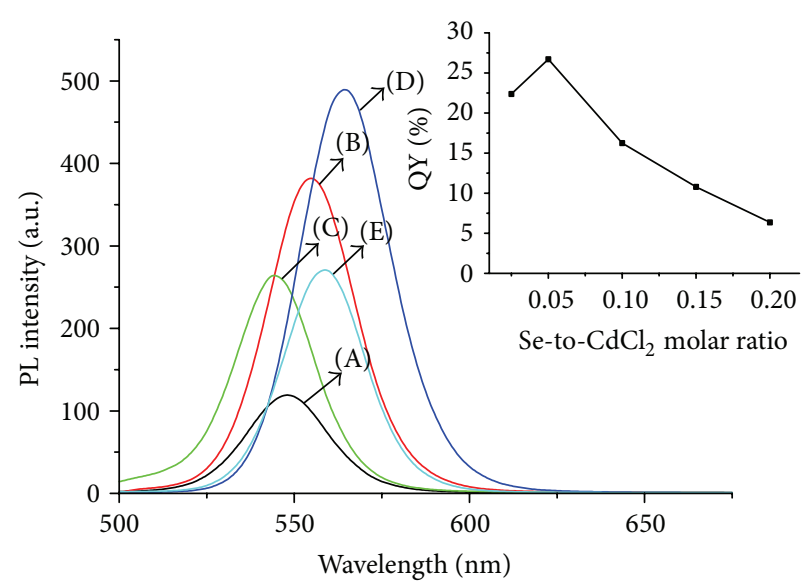

(A): Cd : NAC : Se $=1: 3: 0.025$ (D): Cd : NAC : Se $=1: 3: 0.15$

(B): Cd: NAC: $\mathrm{Se}=1: 3: 0.05$ (E): Cd: NAC: $\mathrm{Se}=1: 3: 0.2$

(C): Cd : NAC : $\mathrm{Se}=1: 3: 0.1$

FIGURE 2: Corrected PL spectra of NAC-capped CdSe QDs grown at different $n(\mathrm{Se}) / 1(\mathrm{Cd})$ values; the inset shows the QYs of these prepared QDs.

on the emission peak of fluorescence spectra $(555 \mathrm{~nm})$ and absorption peak of UV spectra $(533 \mathrm{~nm})$ when $\mathrm{pH}$ value is in the range of 8.5 to 9.5 . However, when $\mathrm{pH}$ reaches the range of 9.5 to 11.0, the emission peak red-shifts to $589 \mathrm{~nm}$ and the UV absorption peak red-shifts to $566 \mathrm{~nm}$, showing that the alkaline environment is beneficial to the reaction speed of the synthesis and further increases the particle diameter of the prepared QDs. The QY reaches the maximum when the $\mathrm{pH}$ is at 9.0.

3.4. Influence of Molar Ratio of NAC to Cd. With other experiment parameters fixed $([\mathrm{Cd}]=6.4 \mathrm{mmol} / \mathrm{L}, n(\mathrm{Cd}): n(\mathrm{Se})$ $=1: 0.05, \mathrm{pH}=9$, reaction time at $65 \mathrm{~min}$, and reaction temperature at $200^{\circ} \mathrm{C}$ ), the impacts of varied amount of the stabilizer NAC upon the prepared CdSe QDs have been studied. As shown in Figure 4, when the molar ratio of $\mathrm{Cd}$ to NAC reaches $1: 3$, the QY of prepared QDs is the highest, and the higher or lower molar ratio would both lead to decreased quantum yield. Since the effect of stabilizer is to inactivate the surface defects of QDs to decrease the nonradioactive recombination, the concentration of the stabilizer is of great significance for the optical properties of prepared QDs. The improper concentration of the stabilizer would greatly lead to debased fluorescence efficiency. The experiments showed that low molar ratio of NAC to $\mathrm{Cd}(1.2: 1)$ led to weak fluorescence intensity, which may be the result of small amount of NAC capped on the surface of QDs caused by shortage of combination sites [8]. When the molar ratio of NAC to Cd rose to $3: 1$, the fluorescence intensity of prepared CdSe QDs is greatly improved with the emission peak redshifting from $523 \mathrm{~nm}$ to $555 \mathrm{~nm}$ and the absorption peak red-shifting from $500 \mathrm{~nm}$ to $523 \mathrm{~nm}$. This is because the high ratio of NAC would greatly lessen the surface defects on the surface of QDs $[9,10]$. The $S^{2-}$ ions released from the decomposition of NAC under high temperature dope 


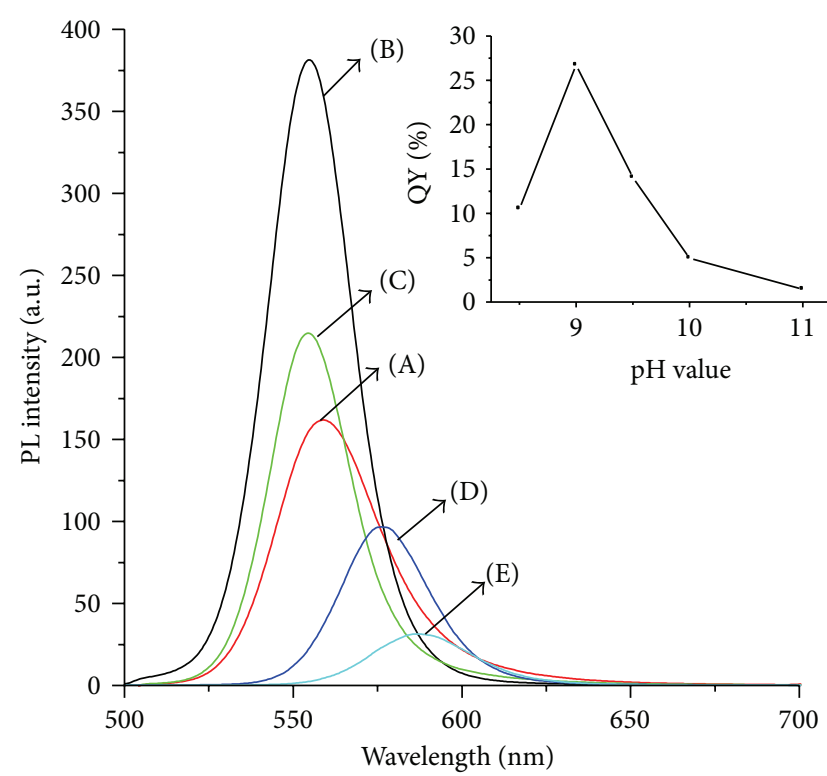
(A): $\mathrm{pH}=8.5$
(B): $\mathrm{pH}=9.0$
(D): $\mathrm{pH}=10$
(E): $\mathrm{pH}=11$

(C): $\mathrm{pH}=9.5$

(a)

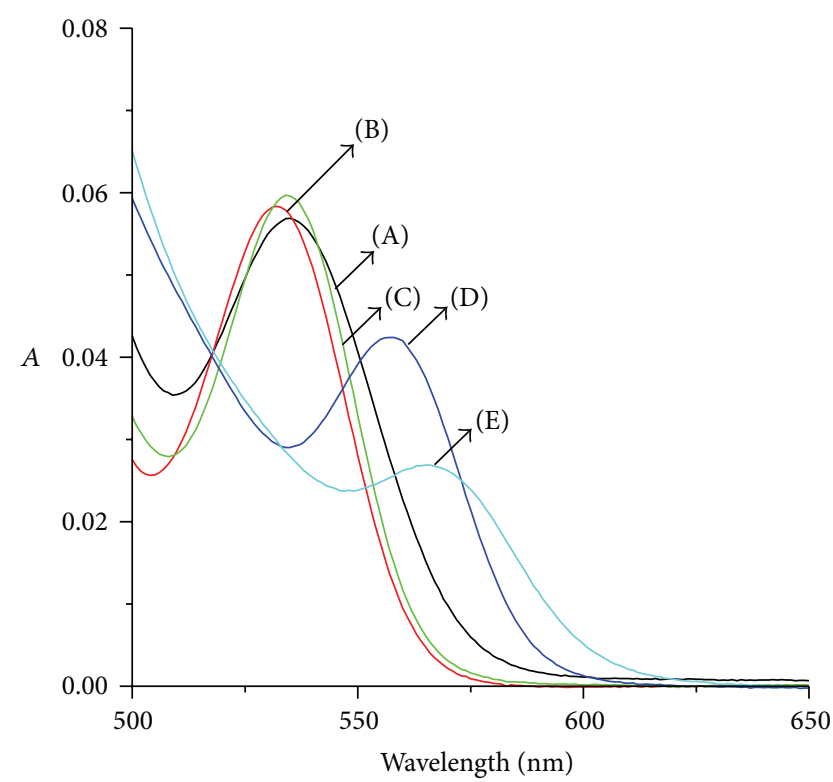
(A): $\mathrm{pH}=8.5$
(B): $\mathrm{pH}=9.0$
(D): $\mathrm{pH}=10$
(E): $\mathrm{pH}=11$

(C): $\mathrm{pH}=9.5$

(b)

FIgURE 3: (a) Corrected PL spectra and (b) UV-visible absorption spectra of NAC-capped CdSe QDs grown at different pH values; the inset shows the QYs of these prepared QDs.

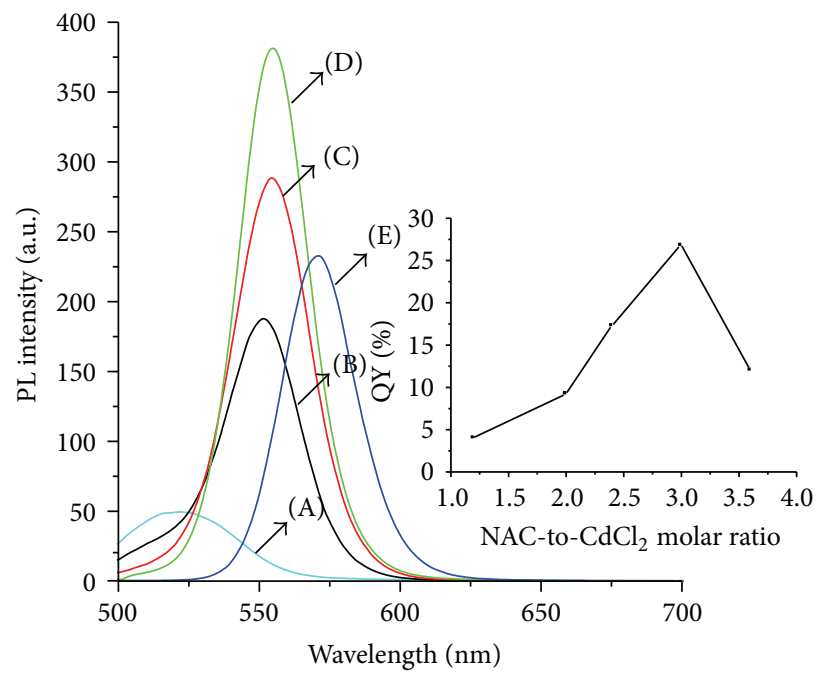
(A): $\mathrm{Cd}: \mathrm{Se}: \mathrm{NAC}=1: 0.05: 1.2$
(D): $\mathrm{Cd}: \mathrm{Se}: \mathrm{NAC}=1: 0.05: 3.0$
(B): $\mathrm{Cd}: \mathrm{Se}: \mathrm{NAC}=1: 0.05: 2.0$
(C): $\mathrm{Cd}: \mathrm{Se}: \mathrm{NAC}=1: 0.05: 2.4$
(E): $\mathrm{Cd}: \mathrm{Se}: \mathrm{NAC}=1: 0.05: 3.6$

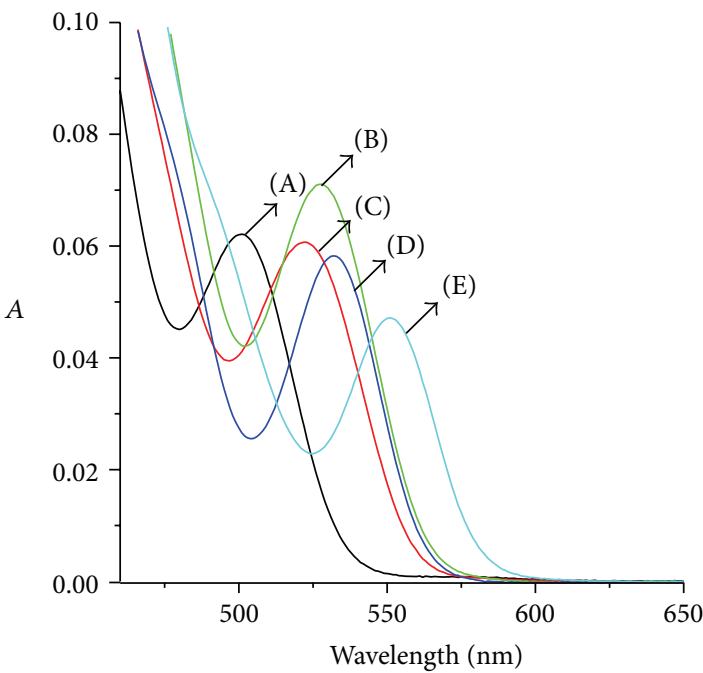
(A): $\mathrm{Cd}: \mathrm{Se}: \mathrm{NAC}=1: 0.05: 1.2$
(D): $\mathrm{Cd}: \mathrm{Se}: \mathrm{NAC}=1: 0.05: 3.0$
(B): $\mathrm{Cd}: \mathrm{Se}: \mathrm{NAC}=1: 0.05: 2.0$
(E): $\mathrm{Cd}: \mathrm{Se}: \mathrm{NAC}=1: 0.05: 3.6$
(C): $\mathrm{Cd}: \mathrm{Se}: \mathrm{NAC}=1: 0.05: 2.4$

(b)

FIGURE 4: (a) Corrected PL spectra and (b) UV-visible absorption spectra of NAC-capped CdSe QDs grown at different $n(\mathrm{NAC}) / 1(\mathrm{Cd})$ values; the inset shows the QYs of these prepared QDs.

with Cd and form CdS onto the surface of QDs, effectively inactivating the surface defects of QDs [9]. Moreover, the formation of CdS can increase the particle diameter of the QDs and decrease the band gap energy, leading to the red shift of the absorption peak. However, when the molar ratio is too high, the formation of more stable dithio complexes between NAC and Cd can lessen the concentration of free $\mathrm{Cd}$ ions, increase the molar ratio of Se in the prepared CdSe QDs, and lead to more surface defects and thus low QYs [17]. 
Through a series of optimal experiments, the optimum synthesis parameters for NAC-capped CdSe QDs have been acquired: $[\mathrm{Cd}]=6.4 \mathrm{mmol} / \mathrm{L}, n(\mathrm{Cd}): n(\mathrm{Se}): n(\mathrm{NAC})=$ $1: 0.05: 3.0$, reaction temperature at $200^{\circ} \mathrm{C}$, reaction time at $65 \mathrm{~min}$, and $\mathrm{pH}=$ 9.0. The QY of prepared CdSe QDs under such optimum condition is $26.7 \%$. The properties of QDs have been examined via HRTEM, XRD, XPS, and EDS, and the mechanism of $S$ ions doping on the surface of CdSe QDs has been further proven via these characterization methods.

3.5. Characterization via XRD and HRTEM. The morphology of the as-prepared NAC-capped CdSe QDs was studied by HRTEM. Figure 5 depicts the HRTEM image for asprepared nanoparticles; the HRTEM image of single QD and electron diffraction pattern (SAED) are shown as insets, demonstrating the relatively narrow size distribution and spherical morphologies of the prepared QDs. The presence of lattice planes in the high resolution image confirms that the nanocrystals have better crystallinity which is further supported by the SAED pattern. In addition, it is noticed that the as-prepared nanoparticles possess good dispersivity. The HRTEM images of the prepared nanoparticles show the average particles sizes of $5.4 \mathrm{~nm}$. The diameter of the prepared particles is in consistency with the already reported core/shell structure model for CdSe/CdS sample ( $5 \mathrm{~nm}$ ) [19] and larger than that of the CdSe nanoparticles $(3.5 \mathrm{~nm})$ [20], which implies a core/shell structure.

The powder XRD patterns of NAC-capped CdSe QDs are shown in Figure 6. In the XRD pattern of prepared QDs, three characteristic diffraction peaks at $2 \theta=26.44,43.56$, and 50.38 degrees standing for the (111), (220), and (311) planes of cubic zinc blende CdSe/CdS could be recognized clearly. In comparison with the XRD pattern of the CdSe QDs [21], the three diffraction peaks only shifted slightly toward larger angles of the values for CdS [22], which demonstrated the formation of the CdS shell on the surface of the CdSe QD. This shows that NAC not only can combine onto the surface of QDs through the combination of its hydrosulfide group with Cd of QDs, but also can release $\mathrm{S}^{2-}$ under high temperature to form doped CdS on the surface of CdSe QDs $[9,10]$.

3.6. Characterization via XPS. XPS is a quantitative, surface analytical tool sensitive to the atomic composition of the outermost $100 \AA$ of a sample surface. As shown in Figure 7, the Cd (3d) peak at a binding energy of $404.03 \mathrm{eV}$, Se (3d) at $53.2 \mathrm{eV}$, and $\mathrm{S}(3 \mathrm{~d})$ at $162.0 \mathrm{eV}$ are the characteristic peaks of CdSe QDs, showing the existence of Cd, Se, and S elements.

3.7. Characterization via EDS. The EDS technique has been employed to probe a semiquantitative picture of the composition of the NAC-capped CdSe QDs. As shown in Figure 8, the atom percentages of $\mathrm{Cd}$, Se, and $\mathrm{S}$ reach $45.98 \%, 3.96 \%$, and $50.06 \%$, respectively. The $\mathrm{S}$ element in QDs derives from the ligand NAC on the surface of QDs, and the high percentage of $S$ is partly the result of the doped CdS on the surface of QDs, which also provides evidence for doping of $S$ on QDs surface.

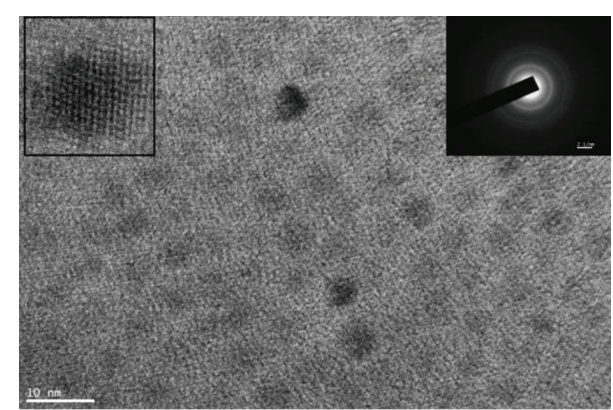

Figure 5: HRTEM image of NAC-capped CdSe QDs reacted for $65 \mathrm{~min}$. The inset shows the HRTEM image of a single CdSe quantum dot (left) and electron diffraction (SAED) pattern (right).

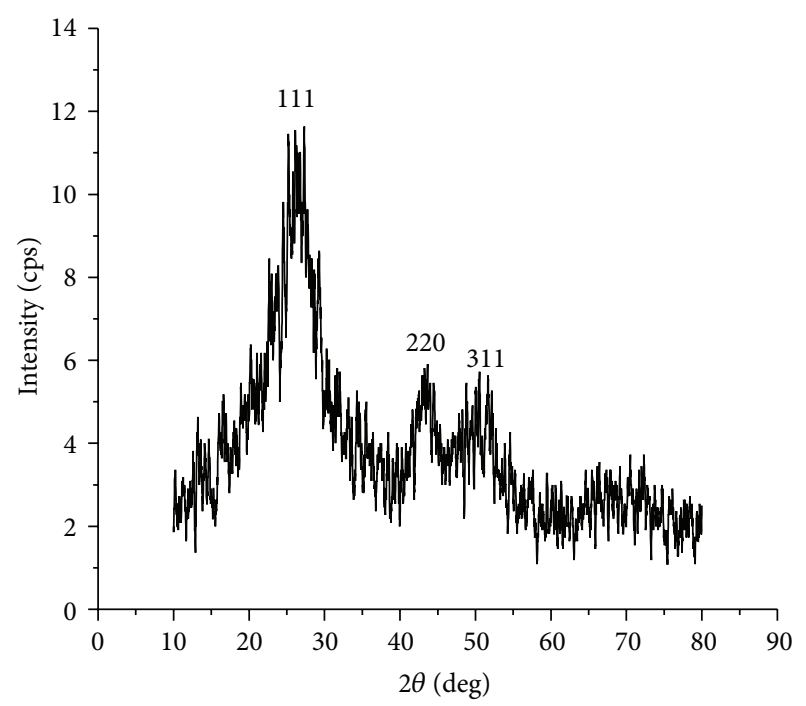

FIGURE 6: XRD pattern of NAC-capped CdSe QDs reacted for $65 \mathrm{~min}$.

3.8. The Impact of $p H$ of $Q D$ s Solution on Their Fluorescence Intensity. The $\mathrm{pH}$ value of the QDs solution would greatly influence its fluorescence intensity and thus its practical applications in biochemistry fields. As shown in Figure 9, the as-prepared QDs show excellent stability when the $\mathrm{pH}$ value of the solution is in the range of 4 to 9 , better than MSA capped CdSe QDs [13]. The too low or too high pH value would lead to weakened fluorescence intensity. This is because the protonation of NAC under acid condition would cause the detachment of NAC from the surface of QDs, leading to the decrease of fluorescence intensity; when $\mathrm{pH}$ value of the solution surpasses 9 , the fluorescence weakens because of the formation of the precipitant $\mathrm{Cd}(\mathrm{OH})_{2}$ [13]. Since the prepared NAC-capped CdSe QDs possess good stability under common biochemical conditions, they will surely be suitable for the applications in the biochemical detections.

\section{Conclusion}

The high-quality NAC-capped CdSe QDs have been prepared via one-step hydrothermal method with NAC as the 


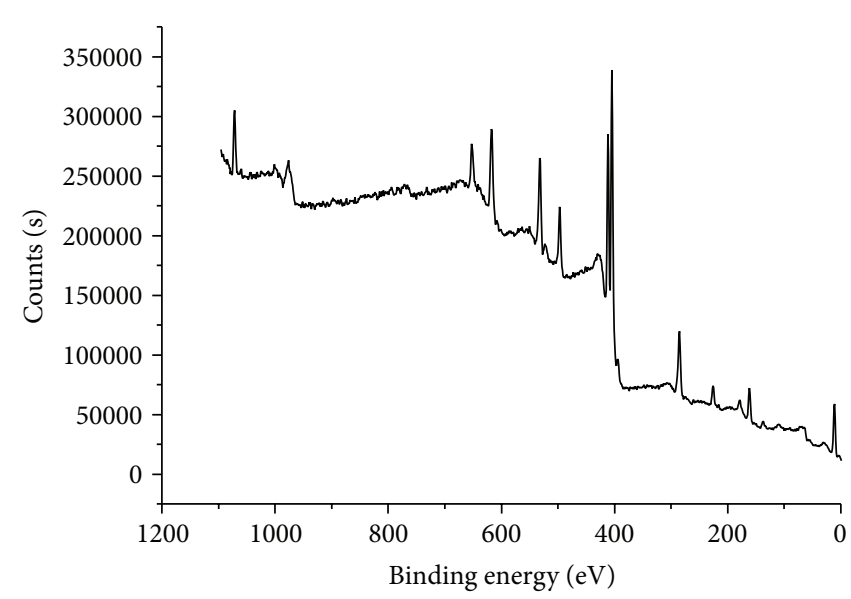

(a)

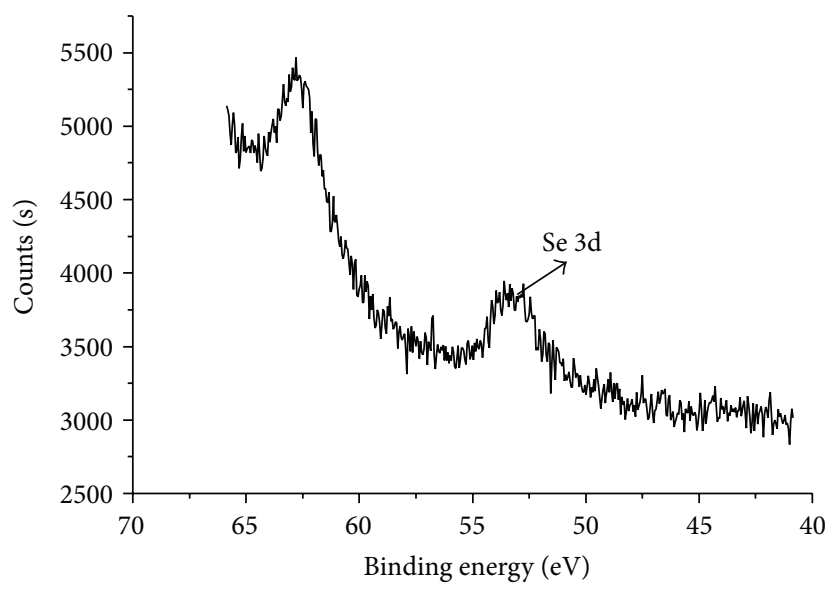

(c)

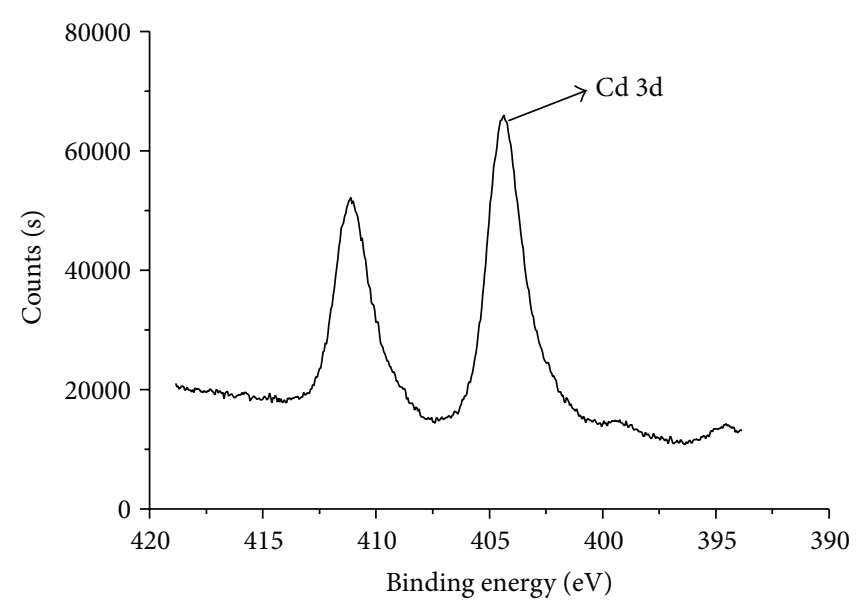

(b)

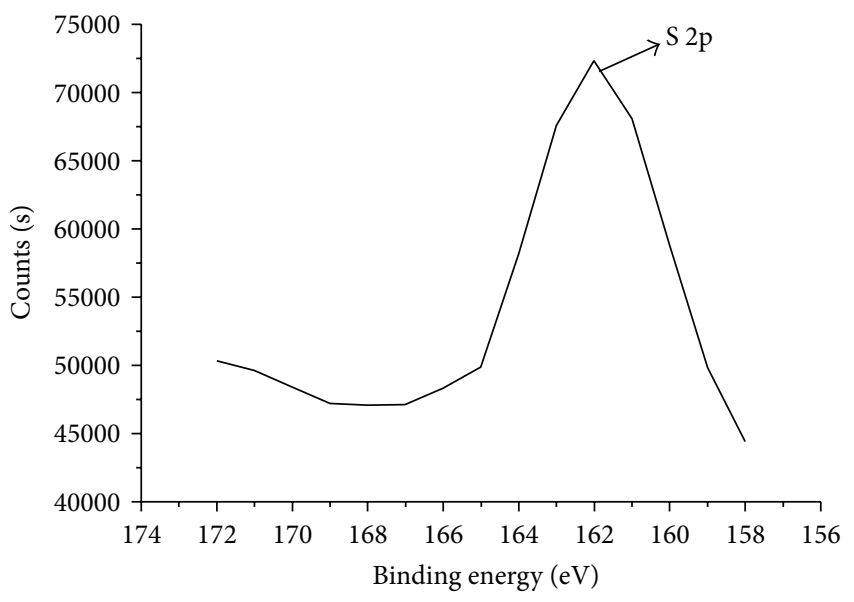

(d)

FIgURE 7: XPS spectra recorded from CdSe QDs: (a) overall picture, (b) Cd(3d), (c) Se(3d), and (d) S(2p).

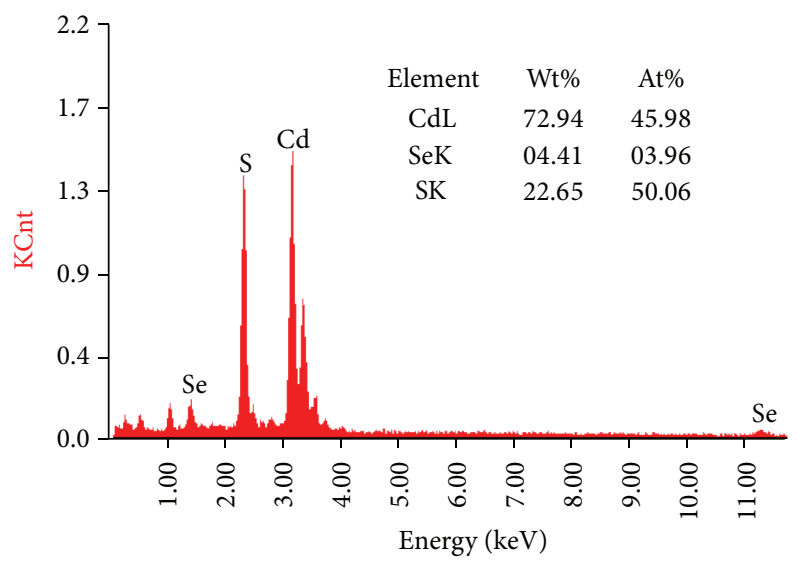

Figure 8: EDS spectrum of NAC-capped CdSe QDs at the molar ratio of $\mathrm{Cd}: \mathrm{Se}=1: 0.05$.

stabilizer. The optimum synthesis parameters have been found, and the prepared CdSe QDs have been characterized in morphology and crystal structure via HRTEM and XRD.

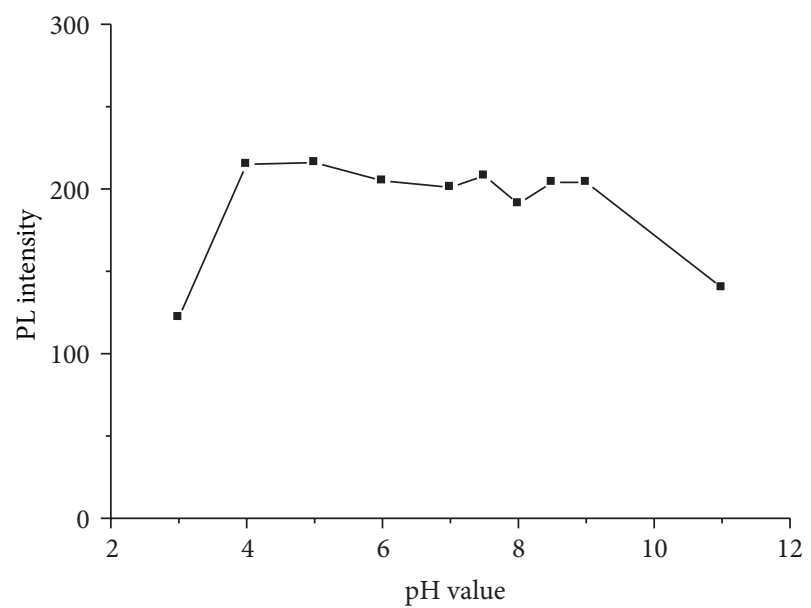

Figure 9: PL intensity of NAC-capped CdSe QDs at various $\mathrm{pH}$ values.

It is found that the particle size of CdSe QDs is smaller than that of CdSe/CdS, and their crystal structure is not 
standard CdSe cubic crystal system but close to CdS cubic crystal system. The XPS image shows the existence of $\mathrm{Cd}$, $\mathrm{Se}$, and $\mathrm{S}$ elements, and $\mathrm{S}$ atomic percentage calculated by EDs is relatively high. All these evidences prove the doping of S on the surface of CdSe QDs. The prepared NAC-capped CdSe QDs are stable with good monodispersity and high QY, ensuring their promising application in biochemistry detections and biomedical researches.

\section{Conflict of Interests}

The authors declare that there is no conflict of interests regarding the publication of this paper.

\section{Acknowledgments}

This research was supported by the National Science Foundation of China (21105130) and Innovation Training Project for College Students (GXX14210).

\section{References}

[1] F. H. Huang, C. Cheng, and C. Sun, "Synthesis and characterization of water-soluble citrate-capped CdSe quantum dots," Chemical Research, vol. 24, p. 1, 2013.

[2] Z. L. Xu, K. Y. Yi, Z. N. Ma, M. Wang, and X. F. Liu, "Synthesis of CdSe quantum dots and their applications for labeling of latent fingerprints," Synthetic Materials Aging and Application, vol. 42, p. 15, 2013.

[3] Q. Wang, F. Ye, T. Fang et al., "Bovine serum albumin-directed synthesis of biocompatible CdSe quantum dots and bacteria labeling," Journal of Colloid and Interface Science, vol. 355, no. 1, pp. 9-14, 2011.

[4] A. C. A. Silva, S. L. V. D. Deus, M. J. B. Silva, and N. O. Dantas, "Highly stable luminescence of CdSe magic-sized quantum dots in HeLa cells," Sensors and Actuators B: Chemical, vol. 191, pp. 108-114, 2014.

[5] X. D. Guo, B. B. Ma, L. D. Wang, R. Gao, H. P. Dong, and Y. Qiu, "Electron injection and photovoltaic properties in CdSe/ZnS quantum dot sensitized solar cells," Acta PhysicoChimica Sinica, vol. 29, pp. 1240-1246, 2013.

[6] L. Z. Du and Y. A. Lei, "Synthesis of high-quality Cl-doped CdSe nanobelts and their application in nanodevices," Materials Letters, vol. 106, pp. 100-103, 2013.

[7] D.-W. Deng, J.-S. Yu, and Y. Pan, "Water-soluble CdSe and CdSe/CdS nanocrystals: a greener synthetic route," Journal of Colloid and Interface Science, vol. 299, no. 1, pp. 225-232, 2006.

[8] K. Wang, H. Q. Pan, S. Y. Liu, X. M. Xu, and L. Y. Zhou, "Preparation and characterization of high quality CdSe quantum dots in aqueous solution," Chemical Journal of Chinese Universities, vol. 33, no. 12, pp. 2604-2608, 2012.

[9] Z. K. Zhao, Z. K. He, and M. M. F. Chanand, "Synthesis and characterization of high-quality water-soluble near-infraredemitting $\mathrm{CdTe} / \mathrm{CdS}$ quantum dots capped by N-acetyl-Lcysteine via hydrothermal method," The Journal of Physical Chemistry C, vol. 113, p. 1293, 2009.

[10] Q. Wang, X. Zhou, T. Fang, P. Liu, X. Li, and X. Min, “One-step growth of high-quality CdTe quantum dots via hydrothermal method and cytotoxicity evaluation," Powder Technology, vol. 247, pp. 81-86, 2013.
[11] X. L. Rong, Q. Zhao, and G. H. Tao, "Aqueous synthesis of CdSe and CdSe/CdS quantum dots with controllable introduction of Se and S sources," Chinese Chemical Letters, vol. 23, no. 8, pp. 961-964, 2012.

[12] Y. Li, L. Liu, X. Fang, J. Bao, M. Han, and Z. Dai, "Electrochemiluminescence biosensor based on CdSe quantum dots for the detection of thrombin," Electrochimica Acta, vol. 65, pp. 1-6, 2012.

[13] S. T. Chen, X. L. Zhang, Q. H. Zhang et al., "CdSe quantum dots decorated by mercaptosuccinic acid as fluorescence probe for $\mathrm{Cu}^{2+}$," Journal of Luminescence, vol. 131, no. 5, pp. 947-951, 2011.

[14] T. Xuan, X. Wang, G. Zhu, H. Li, L. Pan, and Z. Sun, “One-step microwave-assisted synthesis of water soluble CdSe quantum dots for white light-emitting diodes with excellent color rendering," Journal of Alloys and Compounds, vol. 558, pp. 105-108, 2013.

[15] D. W. Ayele, H. M. Chen, W. N. Su et al., "Controlled synthesis of CdSe quantum dots by a microwave-enhanced process: a green approach for mass production," Chemistry, vol. 17, no. 20, pp. 5737-5744, 2011.

[16] M. M. Moghaddam, M. Baghbanzadeh, A. Keilbach, and C. O. Kappe, "Microwave-assisted synthesis of CdSe quantum dots: Can the electromagnetic field influence the formation and quality of the resulting nanocrystals?" Nanoscale, vol. 4, no. 23, pp. 7435-7442, 2012.

[17] J. T. Li, T. M. Yang, W. H. Chan, M. M. F. Choi, and D. Zhao, "Synthesis of high-quality N-acetyl-L-cysteine-capped CdTe quantum dots by hydrothermal route and the characterization through MALDI-TOF mass spectrometry," The Journal of Physical Chemistry C, vol. 117, p. 19175, 2013.

[18] R. Xie, U. Kolb, J. Li, T. Basché, and A. Mews, "Synthesis and characterization of highly luminescent CdSe-core $\mathrm{CdS} / \mathrm{Zn}_{0.5} \mathrm{Cd}_{0.5} \mathrm{~S} / \mathrm{ZnS}$ multishell nanocrystals," Journal of the American Chemical Society, vol. 127, no. 20, pp. 7480-7488, 2005.

[19] A. R. B. Suganthi, A. G. Joshi, and P. Sagayaraj, "A novel twophase thermal approach for synthesizing CdSe/CdS core/shell nanostructure," Journal of Nanoparticle Research, vol. 14, no. 2, article 691, 2012.

[20] K. B. Subila, G. Kishore Kumar, S. M. Shivaprasad, and K. George Thomas, "Luminescence properties of CdSe quantum dots: Role of crystal structure and surface composition," Journal of Physical Chemistry Letters, vol. 4, no. 16, pp. 2774-2779, 2013.

[21] R. M. Hodlur and M. K. Rabinal, "A new selenium precursor for the aqueous synthesis of luminescent CdSe quantum dots," Chemical Engineering Journal, vol. 244, pp. 82-88, 2014.

[22] A. Samadi-maybodi, F. Abbasi, and R. Akhoondi, "Aqueous synthesis and characterization of CdS quantum dots capped with some amino acids and investigations of their photocatalytic activities," Colloids and Surfaces A: Physicochemical and Engineering Aspects, vol. 447, pp. 111-119, 2014. 

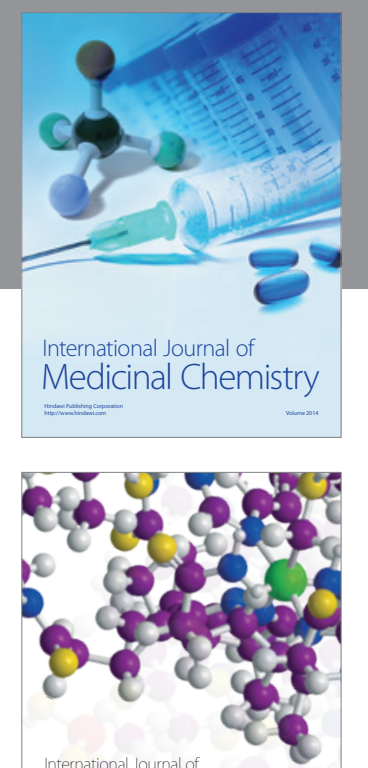

\section{Carbohydrate} Chemistry

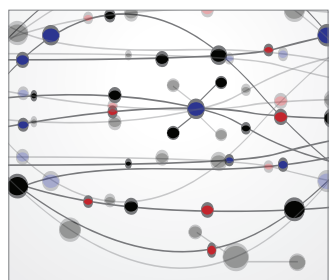

The Scientific World Journal
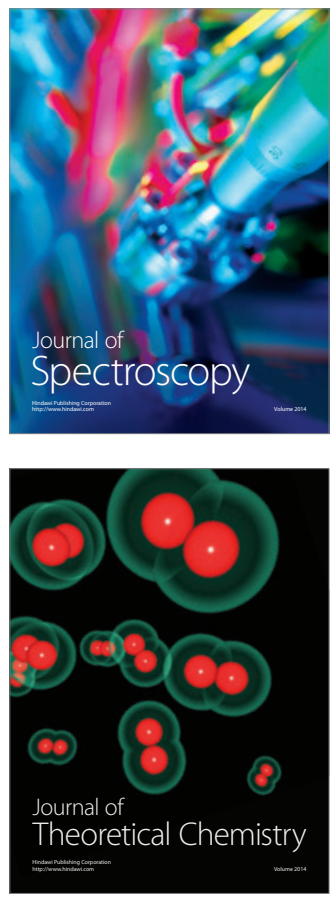
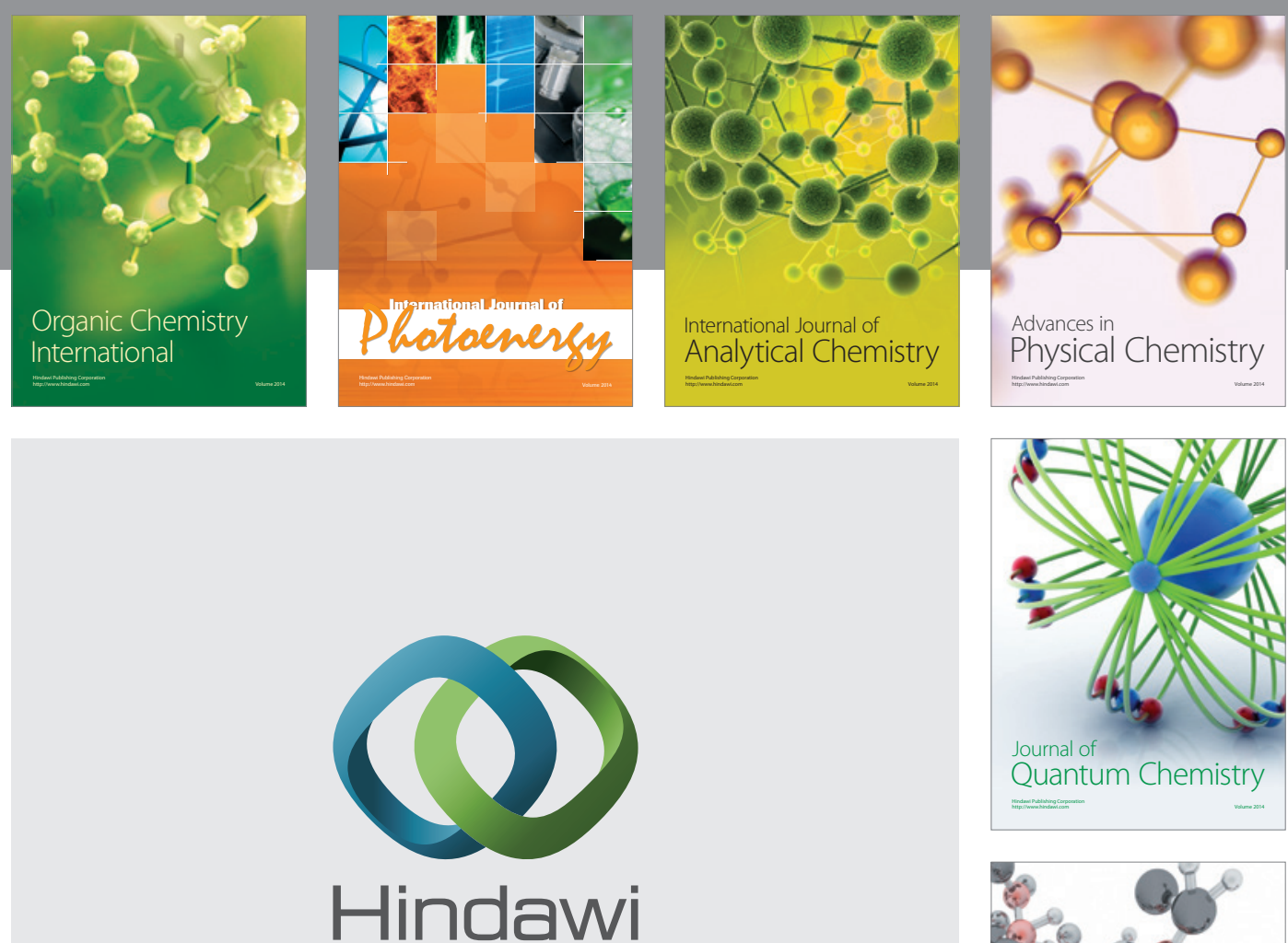

Submit your manuscripts at

http://www.hindawi.com

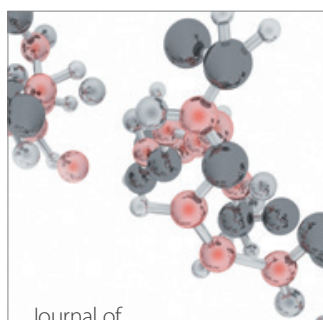

Analytical Methods

in Chemistry

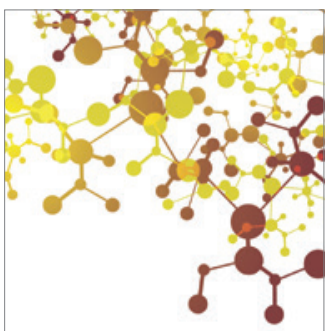

Journal of

Applied Chemistry

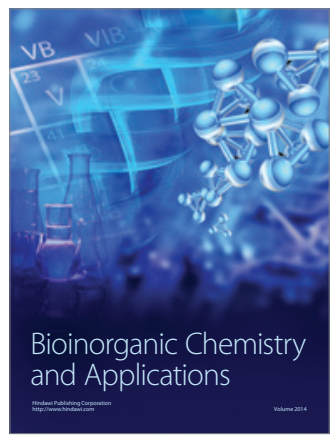

Inorganic Chemistry
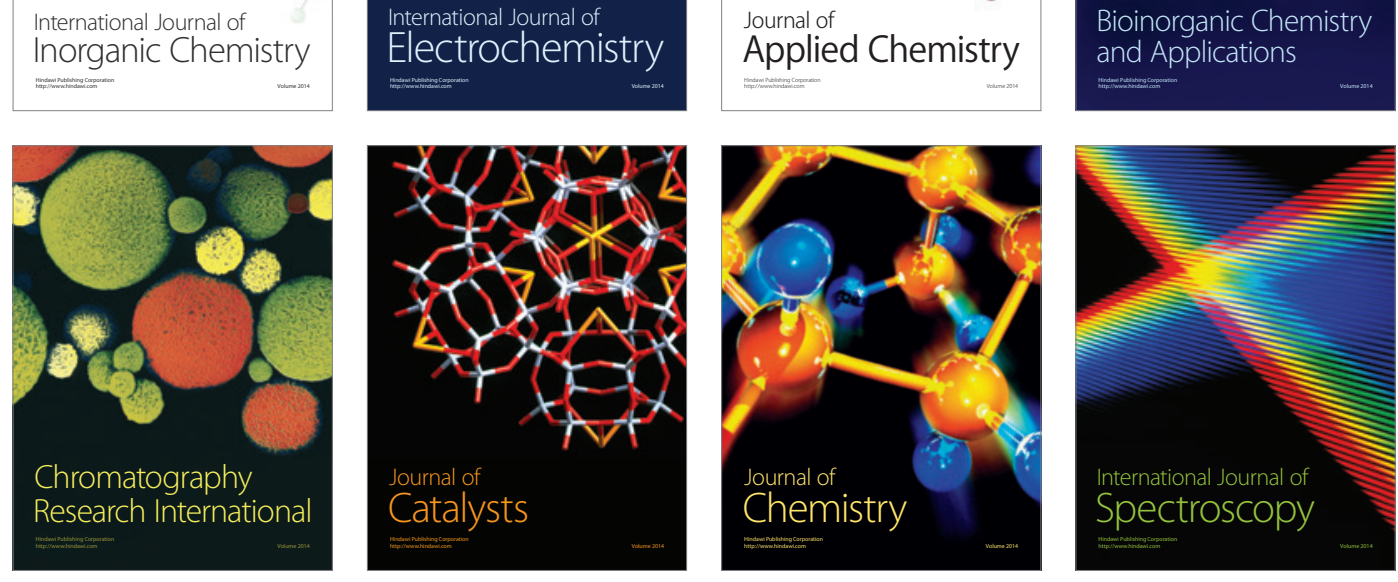